\title{
Nutritional status of school-aged children and its relation to blood pressure
}

\author{
Nora Zeberio, M.D., ${ }^{a}$ Agustina Malpeli, B.S., ${ }^{b}$ María Apezteguía, B.S., \\ Marta A Carballo, B.S, ${ }^{c}$ and Horacio F. González, M.D. ${ }^{b}$
}

\section{ABSTRACT}

Introduction. Obesity is associated with a wide range of cardiovascular and metabolic diseases. Objective. To establish an association between the nutritional status of 6-10 year old boys and girls and blood pressure.

Population and Methods. A cross-sectional, analytical study was conducted in 6-10 year old schoolboys and schoolgirls. Outcome measures and indicators studied included nutritional status as per body mass index; presence of central fat mass distribution estimated by waist circumference; and blood pressure (height, age and gender tables). Differences in mean values were analyzed using a Student's $t$ test. The relationship between outcome measures was estimated using Pearson's correlation coefficient. Linear regression models were adjusted for systolic blood pressure and diastolic blood pressure using the following explanatory outcome measures: $\mathrm{z}$ scores for body mass index, age, gender and waist circumference.

Results: Five hundred and fifty five male and female children were evaluated; they were all younger than 11 years old. A total of $26.3 \%$ was overweight and $15.1 \%$ was obese. The prevalence of hypertension was $1.08 \%$. Results show a positive linear relationship between systolic and diastolic blood pressure, and age and waist circumference, and a trend is observed between systolic blood pressure and the body mass index z score $(p=0.068)$.

Conclusion. Overweight and obesity were the most common nutritional disorders in schoolaged children in the studied district; there is an association between age, waist circumference, and systolic and diastolic blood pressure, and between systolic blood pressure and the body mass index $\mathrm{z}$ score.

Key words: children, nutritional status, obesity, overweight, prevalence, hypertension.

http: / /dx.doi.org/10.5546/aap.2013.92

\section{INTRODUCTION}

Malnutrition, either caused by deficiencies or excesses, is a key indicator to recognize health and development of the population.

Childhood obesity is a serious public health problem in Argentina. ${ }^{1} \mathrm{~A}$ remarkable increase in the prevalence of weight excess has been reported in Latin America and the Caribbean. ${ }^{2}$ The highest overweight and obesity rates are observed in the United States and Europe, but this increasing trend is generalized in countries as varied as China and Brazil. ${ }^{2}$

In the National Survey on Nutrition and Health in Argentina (ENNyS, for its acronym in Spanish) carried out by the Ministry of Health of Argentina, it is reported that the national mean prevalence of obesity was $4.4 \%$ (95\% CI 3.8-5.1) in male and female children aged 6-72 months old as per the Sociedad Argentina de Pediatría (SAP) curves. However, if we use the World Health Organization (WHO) curves, the prevalence of obesity was $10.4 \%$ (95\% CI 9.3-11.5) in children aged 6-60 months old. ${ }^{3}$ In our country, in girls aged 10-14.9 years old, the prevalence of overweight and obesity was $23.5 \%$ and $5.8 \%$, respectively, according to the body mass index (BMI) indicator. ${ }^{3}$

SAP's Consensus on cardiovascular disease risk factors in pediatrics considers the prevalence of obesity in children of different age groups; ${ }^{4}$ in addition, it points out that there are a few studies in 6-10 year old children.

A study conducted in 6-13 year old schoolchildren in the City of Buenos Aires, not representative of the general population, showed a prevalence of overweight and obesity of $29 \%$ and $12.3 \%$, respectively. ${ }^{5}$ In a different study conducted in Santa Teresita, Province of Buenos Aires, in children aged 6-10 years the overall prevalence of overweight and obesity was $34.6 \%$ and $17.9 \%$, respectively. ${ }^{6}$

In childhood, the interaction between genetic, biological, psychological, socio-cultural and environmental factors is clear. ${ }^{7}$ In a child under 3 
years old, if his/her father is obese, the odds ratio (OR) of that child to develop obesity at adulthood is 3 , but if both parents are obese, the OR is more than 10. Before 3 years old, parent's obesity is a stronger predictor of adult obesity than the child's weight. ${ }^{\text {? }}$

National and international publications have shown an association between the nutritional status and cardiovascular risk. Recent publications in Argentina have shown that obese children and adolescents are more likely to have hypertension. ${ }^{6,8}$ Other countries have published the same findings regarding a positive association between obesity and hypertension. ${ }^{9,10}$

In pediatrics, the increase in obesity has led to hypertension being more frequent during childhood, affecting $1-9 \%$ of children and up to $10 \%$ of adolescents. ${ }^{5-10}$

These observations have significant implications for the identification of such risk and the need to approach this issue by means of guidelines aimed at preventive healthy routines, regarding both feeding and healthy physical activity patterns.

Treatments may help control childhood obesity in the short term, but since long term weight control is difficult, prevention is still the best therapeutic tool. ${ }^{6}$

The objective of this study was to examine the nutritional status of a 6-10 year old population of male and female children attending schools in the district of Olavarría, Province of Buenos Aires, Argentina, and to establish its relation to blood pressure.

\section{POPULATION AND METHODS}

Design: Cross-sectional, analytical study.

Study location: The district of Olavarría is located in the Province of Buenos Aires, Argentina $\left(37^{\circ} \mathrm{S}, 60^{\circ} \mathrm{W}\right)$. There, the percentage of population with unmet basic needs is $8.31 \%$. The percentage of the population with a sewer system is $46.7 \%$ and with access to drinking water $71 \%$. The percentage of illiteracy is $0.68 \%$ and that of unemployment reaches $11.3 \%$. The total number of students enrolled in first to fifth grades in primary schools is 27056 .

Inclusion criteria: 6-10 year old male and female children attending public and private schools who accepted to participate in the study.

Exclusion criteria: presence of acute or chronic diseases.

In order to estimate the prevalence of obesity with a $3.2 \%$ accuracy and a 95\% confidence level, and considering that the expected prevalence of obesity was less than $20 \%$ based on previous studies, it was determined that the required sample size would be approximately 600 children.

Six sports facilities where public and private school children play sports were randomly selected from different parts of the city. All children attending such facilities were examined on the scheduled visit day to determine whether they met the inclusion and exclusion criteria. Visits took place in March 2009.

\section{OUTCOME MEASURES \\ Nutritional status \\ Nutritional status indicators}

All indicators were evaluated as per WHO's tables using the AnthroPlus software. $Z$ scores were estimated as follows: height for age (z-HA), weight for age (z-WA) and body mass index (zBMI). Weight and height measures were taken by a single observer using the technique and procedures recommended for the age. ${ }^{11}$ Participants were weighted wearing trousers and a T-shirt, with no shoes on. The weight of clothes was then subtracted to obtain the body weight value. A digital electronic ASPEN scale with a $100 \mathrm{~g}$ range was used. For measuring height, a CAM infantometer with a $1 \mathrm{~mm}$ accuracy was employed.

Presence of overweight and obesity

Indicator: body mass index (BMI) (weight/ height ${ }^{2}$ ). Overweight: $z-B M I$ between +1 and +2 , obesity: z-BMI $>+2 .{ }^{12}$

Presence of underweight

Indicator: weight/age (W/A), underweight: z$\mathrm{BMI}<-2$. $^{12}$

Presence of chronic growth retardation (CGR)

Indicator: height/age (H/A), chronic growth retardation: $\mathrm{z}-\mathrm{HA}<-2{ }^{12}$

Waist circumference (WC) was measured by the same observer, as per the recommendations, ${ }^{13}$ using an unstretchable tape, with the child standing in an anatomical position and both arms on the sides, at the end of an exhalation.

Presence of central fat mass distribution.

Indicator: $\mathrm{WC}$, with central obesity defined as a $W C \geq 90^{\text {th }}$ percentile. ${ }^{13}$

\section{Blood pressure}

Blood pressure (BP) was measured according to the American Heart Association guidelines, ${ }^{14}$ using an Omron ${ }^{\circledR}$ automatic blood pressure monitor with $8 / 9 \mathrm{~cm}$ and $10 / 12 \mathrm{~cm}$ cuffs.

Presence of hypertension

Indicator: blood pressure; risk for hyperten- 
sion was defined as the presence of a blood pressure value $>90^{\text {th }}$ percentile, and hypertension as a value $>95^{\text {th }}$ percentile, as per age, height, gender and blood pressure tables. ${ }^{14}$

\section{Statistical analysis}

Data were analyzed using the SPSS software. Differences in means were analyzed using Student's $t$ test. The relationship between outcome measures was estimated using Pearson's correlation coefficient.

Linear regression models were adjusted for systolic blood pressure (SBP) and diastolic blood pressure (DBP) using z-BMI, age, gender and waist circumference as explanatory outcome measures.

\section{Ethical considerations}

The protocol was approved by the Institutional Research Protocol Review Committee of the Pediatric Research and Development Institute (Instituto de Desarrollo e Investigaciones Pediátricas, IDIP) Prof. Dr. Fernando Viteri, Hospital de Niños Sor María Ludovica, of La Plata.

The School Board of Olavarría and the authorities of the schools where the exams were conducted provided their authorization for the study. Informed consent forms were completed and signed by parents, and children older than 8 years old gave their informed assent.

\section{RESULTS}

A total of 555 children (F: 259; M: 296) under 11 years old attending first-fifth grade in a primary school were evaluated.

In the studied population, underweight was present in $0.4 \%(\mathrm{z}-\mathrm{WA}<-2)$ and $5.8 \%$ had chronic growth retardation $(\mathrm{z}-\mathrm{HA}<-2)$. The nutritional status of the studied population as per the BMI indicated that $57.3 \%$ were normal, $1.3 \%$ had some degree of malnutrition, $26.3 \%$ was overweight, and $15.1 \%$ was obese.

Hypertension had developed in $1.08 \%$ of the population.

Table 1 shows the waist circumference according to age in boys and girls.

Positive correlations were found between SBP and DBP and z-BMI or waist circumference. The values of the Pearson's correlation coefficient were as follows: for z-BMI and SBP, $r=0.245(p<0.001)$; for $\mathrm{Z}-\mathrm{BMI}$ and DBP, $r=0.167$ $(p<0.001)$; for SBP and waist circumference, $r=0.494(p<0.001)$, and for DBP and waist circumference, $r=0.325(p<0.001)$.
Once linear regression models for SBP were adjusted, the gender outcome measure was not statistically significant. In the adjusted linear regression model for SBP $\left(R^{2}=0.40\right)$, the coefficient for age was $2.75(p=0.000)$; for waist circumference, $0.288(p=0.000)$ and for the $\mathrm{z}$-BMI, 0.61 $(p=0.068)$. This shows that the mean SBP increases with age approximately $2.75 \mathrm{mmHg}$ each year, but a higher waist circumference or z-BMI are also related to an increase in mean SBP.

Once linear regression models for DBP were adjusted, the gender and z-BMI outcome measures were not statistically significant. The adjustment in this DBP model was smaller $\left(\mathrm{R}^{2}=0.148\right)$, and the coefficient was $1.095(p=0.000)$ and 0.204 $(p=0.000)$ for the age and waist circumference outcome measures, respectively.

Table 2 shows a comparison between mean SBP and mean DBP in children with and without central obesity. Both SBP and DBP were higher in children with central obesity $(p=0.001$ and 0.002 , respectively). The difference in the mean DBP value between both groups was $2.7 \mathrm{mmHg}$.

Central obesity distribution was $15.1 \%$ in girls and $13.2 \%$ in boys.

\section{DISCUSSION}

Results found in the studied population of 6-10 year old children show that the most common nutritional disorders are overweight $(26.3 \%)$ and obesity (15.1\%), and these involved over $40 \%$ of our sample. National studies have described si-

TABLE 1. Waist circumference by age in boys and girls

\begin{tabular}{lcc}
\hline Age & Girls & Boys \\
& $\mathbf{n}$ & $\mathbf{n}$ \\
\hline 5 years old & $55.76 \pm 5.07$ & $55.52 \pm 6,08$ \\
& 34 & 44 \\
\hline 6 years old & $57.59 \pm 6.95$ & $57.75 \pm 6.05$ \\
& 49 & 49 \\
\hline 7 years old & $61.23 \pm 7.32$ & $60.28 \pm 8.26$ \\
& 52 & 46 \\
\hline 8 years old & $64.76 \pm 9.26$ & $59.10 \pm 6.02$ \\
& 42 & 39 \\
\hline 9 years old & $62.12 \pm 7.45$ & $64.71 \pm 8.84$ \\
& 54 & 89 \\
\hline 10 years old & $65.32 \pm 7.01$ & $68.42 \pm 10.03$ \\
& 28 & 28 \\
\hline Total & $61.02 \pm 7.97$ & $61.10 \pm 8.68$ \\
& 259 & 295 \\
\hline
\end{tabular}

Results are expressed as mean \pm standard deviation. 
milar tendencies, both in the results published by the $\mathrm{ENNyS}^{3}$ and the studies conducted in different cities or provinces. ${ }^{15} \mathrm{~A}$ few studies focused on poverty and carried out over the last decade used national curves as reference and indicated highly variable prevalence figures of overweight and obesity in school-aged children, reaching 9\% and $13 \%{ }^{16-18}$

The study conducted by the $\mathrm{WHO} / \mathrm{PAHO}$ revealed an increasing obesity trend in developing countries, especially in urban areas..$^{19}$ The results for both Brazil and Chile were similar to those found in our population, ${ }^{20,21}$ with a high prevalence of hypertension of $1.08 \%$ in our sample, which was also similar to that reported in publications regarding the United States population. ${ }^{14}$ Hypertension has a low prevalence in childhood (1-2\%), but increases significantly during adolescence and is particularly associated with overweight and obesity. ${ }^{14,22-24}$

Our results show that SBP and DBP depend on age, nutritional status and waist circumference.

In the Bogalusa study, overweight children had 4.5 and 2.4 more chances of having high SBP and DBP, respectively, than non-overweight children. ${ }^{25}$ In a screening conducted by Sorof, et al. in an adolescent population of eight public schools in Texas (USA) a three times higher prevalence of high blood pressure was observed in obese adolescents. ${ }^{26}$

The same risk was observed in children and adolescents studied in Canada. ${ }^{27}$ Hirschler, et al. proved that waist circumference may help identify overweight and obese children at risk of metabolic and cardiovascular complications. ${ }^{5} \mathrm{Ge}-$ novesi, et al. found a strong association between hypertension and increased weight and waist circumference, ${ }^{28}$ while Maffei, et al. observed a positive correlation between the increase in mean waist circumference, insulin resistance and hypertension. $^{29}$

TABLE 2. Systolic blood pressure and diastolic blood pressure by presence or absence of central obesity

\begin{tabular}{lccc} 
& $\begin{array}{c}\text { Children with } \\
\text { central obesity } \\
(\mathbf{n}=\mathbf{7 8})\end{array}$ & $\begin{array}{c}\text { Children without } \\
\text { central obesity } \\
(\mathbf{n}=\mathbf{4 7 7})\end{array}$ & \\
\hline & Mean \pm SD & Mean \pm SD & $P$-value \\
\hline SBP & $98.52 \pm 9.97$ & $94.93 \pm 8.91$ & 0.001 \\
\hline DBP & $61.11 \pm 6.45$ & $58.41 \pm 7.36$ & 0.002 \\
\hline
\end{tabular}

SBP: systolic blood pressure.

DBP: diastolic blood pressure.
Our results demonstrate a positive correlation between central obesity as estimated by waist circumference and blood pressure.

In Sweden, Ruiz, et al. analyzed the association between BMI, waist circumference and blood pressure in an ergometric study conducted in 873 children aged 9-10 years old. Results indicated that an increase in central fat accumulation was positively associated with high blood pressure and reduced exercise cardiorespiratory performance and endurance. ${ }^{30}$

Other studies have related obesity, BMI, waist circumference and blood pressure with biochemical indicators of the metabolic syndrome. Though this was not the aim of our study, it is interesting as a warning regarding other complications inherent to obesity in children and its impact in adult life, and it provides more scientific evidence for an active intervention, towards the prevention of these complications..$^{31-33}$

According to our results, central obesity in the studied children has a significant impact on SBP and, to a lesser extent, on DBP. However, DBP was significantly higher in children with central obesity.

In a very important population study conducted in the United States in an adult 35-64 year old population, authors reported that a reduction of $2 \mathrm{mmHg}$ in mean DBP may lead to a decrease in the prevalence of hypertension of approximately $17 \%$, a reduction in the risk of heart diseases of approximately $6 \%$, and a reduction in the risk of stroke and ischemic transient attacks of about $15 \%$. This means that a small decrease in the distribution of mean DBP may have a great impact on public health in relation to the number of cardiovascular diseases. ${ }^{34}$

Our results showed differences in DBP in school-aged overweight or obese children and this demonstrates the need to implement preventionrelated interventions at an earlier age in childhood in order to promote a healthier lifestyle, which depends on the development of health education activities by government agencies and on food industry cooperation. Overweight and obesity in children can be detected with simple, accessible and low-cost methods, which can be easily implemented in primary healthcare.

Conclusion. Our results indicate that the most common nutritional problem in our studied population is overweight $(26.3 \%)$ and obesity $(15.1 \%)$, that SBP linearly depends on age, z-BMI and waist circumference, and that DBP linearly depends on age and waist circumference. 


\section{BIBLIOGRAPHY}

1. Calvo E. Obesidad infantil y adolescente: un desafío para la prevención. Arch Argent Pediatr 2002;100(5):355-6.

2. Wang Y, Monteiro C, Popkin B. Trends of obesity and underweight in older children and adolescents in the United States, Brazil, China, and Russia. Am J Clin Nutr 2002;75(6):971-7.

3. Ministerio de Salud de la Nación. Encuesta Nacional de Nutrición y Salud ENNyS. Documentos de Resultados. 2007;52-64. [Accessed on 09-26-2012] Available at: http:/ / msal.gov.ar/htm/site/ennys/pdf/documento_resultados_2007_01.pdf

4. Subcomisión de Epidemiología y Nutrición. Consenso sobre factores de riesgo de enfermedad cardiovascular en pediatría. Obesidad. Arch Argent Pediatr 2005;103(3):262-81.

5. Hirschler V, Delfino A, Clemente G, Aranda C y cols. ¿Es la circunferencia de cintura un componente del síndrome metabólico en la infancia? Arch Argent Pediatr 2005;103(1):7-13.

6. Szer G, Kovalskys I, De Gregorio M. Prevalencia de sobrepeso, obesidad y su relación con hipertensión arterial y centralización del tejido adiposo en escolares. Arch Argent Pediatr 2010;108(6):492-8.

7. Krebs NF, Jacobson MS; American Academy of Pediatrics Committee on Nutrition. Prevention of pediatric overweight and obesity. Pediatrics 2003;112(2):424-30.

8. Tringler M, Rodriguez EM, Aguera D, Molina JD, et al. High blood pressure, overweight and obesity among rural scholars from the Vela project: a population-based study from South America. High Blood Press Cardiovasc Prev 2012;19(1):41-6.

9. Falkner B, Daniels S, Horan MJ, Loggie JM, et al. Update on The Task Force Report (1987) on high blood pressure in children and adolescents. Pediatrics 1996;98(4 pt1):649-58.

10. Shi Y, de Groh M, Morrison H. Increasing blood pressure and its associated factors in Canadian children and adolescents from Canadian Health Measures Survey. BMC Public Health 2012;12(1):388.

11. Comité de Crecimiento y Desarrollo. Guías para la evaluación del crecimiento. 2. ${ }^{a}$ ed. Buenos Aires: Sociedad Argentina de Pediatría, 2001.

12. De Onis M, Onyango AW, Borghi E, Garza C, Yang H. Comparison of the World Health Organization (WHO) Child Growth Standards and the National Center for Health Statistics/WHO international growth reference: Implications for child health programmes. Public Health Nutr 2006;9(7):942-7.

13. McCarthy HD, Jarret KV, Crawley HF. Development of waist circumference percentiles in British children aged 5.0 to 16.9 years. Eur J Clin Nutr 2001;55(10):902-7.

14. National High Blood Pressure Education Program Working Group on High Blood Pressure in Children and Adolescents. The Fourth Report on the Diagnosis, Evaluation, and treatment of High Blood Pressure in Children and Adolescents. Pediatrics 2004;114(2 Suppl 4th report):555-76.

15. Chesta M, Lobo B, Agrelo EC, Sabulsky J, et al. Evaluación antropométrica en niños de la Ciudad de Córdoba, año 2000. Arch Argent Pediatr 2007;105(2):101-8.

16. Gullerian AR, Guezikaraian NI, Olivo MS. Situación nutricional de niños en contextos de pobreza de Puerto Iguazú,
Misiones, Argentina. Arch Argent Pediatr 2006;104(5):416-22.

17. Malpeli A, Sala M, Bettiol M, Pattin J y cols. Diagnóstico del estado nutricional de micronutrientes y evaluación antropométrica en una población infantil suburbana de la Provincia de Buenos Aires. Ludovica Pediatr 2006;8(2):4552.

18. Dei-Cas P, Dei-Cas S, Dei-Cas I. Sobrepeso y obesidad en la niñez. Relación con factores de riesgo. Arch Argent Pediatr 2002;100(5):368-73.

19. Uauy R, Albala C, Kain J. Obesity trends in Latin America: Transiting from under-to-overweight. J Nutr 2001;131(3):893s-9s.

20. Triches R, Giugliani E. Obesity, eating habits and nutritional knowledge among school children. Rev Saúde Pública 2005;39(4):541-7.

21. Vio F, Albala C, Kain J. Nutrition transition in Chile revisited: mid-term evaluation of obesity goals for the period 2000-2010. Public Health Nutr 2008;11(4):405-12.

22. Mitsnefes MM. Hypertension in children and adolescents. Pediatr Clin North Am 2006;53(3):493-512.

23. Poletti OH, Pizzorno JA, Barrios L. Valores medios de tensión arterial en escolares de 10 a 15 años de la ciudad de Corrientes, Argentina. Arch Argent Pediatr 2006;104(3):2106.

24. Deregibus M, Haag D, Ferreiro C. Consenso sobre factores de riesgo de enfermedad cardiovascular en pediatría. Arch Argent Pediatr 2005;103(4):348-66.

25. Freedman DS, Dietz WH, Srinivasan SR, Berenson GS. The relation of overweight to cardiovascular risk factors among children and adolescents: the Bogalusa Heart Study. Pediatrics 1999;103(6 pt1):1175-82.

26. Sorof JM, Lai D, Turner J, Poffenbarger T, Portman RJ. Overweight, ethnicity, and the prevalence of hypertension in school-aged children. Pediatrics 2004;113(3 pt1):475-82.

27. Salvadori M, Sontrop JM, Garg A, Truong J, et al. Elevated blood pressure in relation to overweight and obesity among children in a rural Canadian community. Pediatrics 2008;122(4):e821-7.

28. Genovesi S, Antolini L, Giussani M, Pieruzzi F, et al. Usefulness of waist circumference for identification of childhood hypertension. J Hypertens 2008;26(8):1563-70.

29. Maffeis C, Corciulo N, Livieri C, Rabbone I, et al. Waist circumference as a predictor of cardiovascular and metabolic risk factors in obese girls. Eur J Clin Nutr 2003;57(4):566-72.

30. Ruiz JR, Ortega FB, Loit HM, Veidebaum T, Sjöström M. Body fat associated with blood pressure in school-aged girls with low cardiorespiratory fitness: the European Youth Heart Study. J Hypertens 2007;25(10):2027-34.

31. Lee S, Bacha F, Arslanian SA. Waist circumference, blood pressure, and lipid components of the metabolic syndrome. J Pediatr 2006;149(6):809-16.

32. Del-Rio-Navarro BE, Velazquez-Monroy O, Lara-Esqueda A, Violante-Ortiz R, et al. Obesity and metabolic risks in children. Arch Med Res 2008;39(2):215-21.

33. Symonds M, Stephenson T, Budge H. Early determinants of cardiovascular disease: the role of early diet in later blood pressure control. Am JClin Nutr 2009;89(5Suppl):1518s-22s.

34. Cook N, Cohen J, Hebert PR, Taylor JO, Hennekens CH.. Implications of small reductions in diastolic blood pressure for primary prevention. Arch Intern Med 1995;155(7):701-9. 